\title{
Euphorbia grandicornis Sap Keratouveitis: A Case Report
}

\author{
María Gómez-Valcárcel $^{\mathrm{a}} \quad$ Graciana Fuentes-Páez $^{\mathrm{b}}$ \\ ${ }^{a}$ Private Practice and Hospital Ángeles del Pedregal, México City, Mexico; \\ ${ }^{\mathrm{b}}$ Centro MédicoTeknon, Barcelona, Spain
}

\section{Key Words}

Corneal toxicity $\cdot$ Euphorbia $\cdot$ Keratouveitis

\begin{abstract}
Purpose: To describe a case of keratouveitis caused by Euphorbia grandicornis sap, that resolved with topic steroids. Methods: We report a case presentation of a patient with keratouveitis. Results: A 70-year-old woman suffered from accidental ocular contact with $E$. grandicornis sap in her left eye. Two hours after the contact, she attended the clinic due to conjunctival hyperemia and pain. Best-corrected visual acuity (BCVA) was 20/25. The toxic conjunctivitis was treated with topical lubricant and steroid. After $24 \mathrm{~h}$, she presented blurred vision. BCVA was 20/80. Toxic keratouveitis was diagnosed. Topical treatment with $1 \%$ cyclopentolate t.i.d., $5 \%$ sodium chloride, $1.14 \%$ dexamethasone phosphate each hour, and $4 \%$ sodium hyaluronate each hour was continued. Complete resolution was obtained 1 week later. Euphorbia sap content analysis was performed using dissolvent extraction spectrophotometry. Its contents included flavonoids, alkaloids, phenols and sesquiterpene lactones. Conclusion: Corneal exposure to E. grandicornis sap is a cause of nonvisually threatening keratouveitis when adequately treated with corticosteroids.

\section{Introduction}

The genus Euphorbia belongs to a group of plants characterized by tall thick stems, resembling cacti, with a highly corrosive, milky sap [1]. Ocular inflammation due to Euphorbia sap is usually self-limited, though potentially blinding if left untreated [2, 3]. Euphorbiacae keratitis is characterized by initial punctate keratopathy and progression to larger epitheliopathy, with excellent final visual outcome [4]. Euphorbia sap keratouveitis has been associated with exposure to the sap of several Euphorbia species, including lactea, royleana, lathy-

\section{KARGER}


Gómez-Valcárcel and Fuentes-Páez: Euphorbia grandicornis Sap Keratouveitis: A Case Report

ris, trigona, tirucalli, peplus, cyparissias, and helioscopia but not Euphorbia grandicornis [2-4]. We present the clinical evolution of E. grandicornis (Goebel ex N.E.Br.) sap keratouveitis and its chemical components.

\section{Case Presentation}

A 70-year-old female patient, with a history of hip replacement surgery, Barret's esophagus, skin cancer, and treated systemic hypertension, suffered from accidental ocular contact with E. grandicornis sap (fig. 1). She washed her left eye (OS) with water and, after 2 h, she attended the clinic due to OS conjunctival hyperemia and pain.

Her OS was profusely irrigated with saline solution, after which ophthalmology exploration showed a best-corrected visual acuity (BCVA) of 20/15 (+2.75 D) in her right eye (OD) and 20/25 (+2.75 D) in her OS. Intraocular pressure (IOP) was $11 \mathrm{~mm} \mathrm{Hg}$ for both eyes and biomicroscopy was normal in her OD. OS had conjunctival hyperemia, chemosis, a transparent cornea with intact epithelium, and a quiet anterior chamber. Fundoscopy was normal for both eyes. Toxic conjunctivitis was then treated with topical $4 \%$ sodium hyaluronate each hour and $1.14 \%$ dexamethasone (sodium phosphate) 6 times a day. After $24 \mathrm{~h}, \mathrm{BCVA}$ decreased to 20/80 in the OS, IOP was $11 \mathrm{~mm} \mathrm{Hg}$, the conjunctiva remained chemotic, and ciliary flush was present. The cornea of her OS had diffuse punctuate keratitis (fluorescein staining), subepithelial and stromal edema and Descemet folds, while the anterior chamber revealed +++ cells (fig. 2). Fundoscopy was normal. Anterior keratouveitis was then treated with topical $1 \%$ cyclopentolate t.i.d., $5 \%$ sodium chloride t.i.d., $1.14 \%$ dexamethasone phosphate each hour, and $4 \%$ sodium hyaluronate each hour. Additionally, $0.5 \%$ chloramphenicol was added as prophylactic antibiotic.

Three days after the initial insult, the BCVA in her OS was 20/60, IOP was $11 \mathrm{~mm} \mathrm{Hg}$, chemosis had improved, subepithelial and stromal edema as well as Descemet folds persisted, and anterior chamber inflammation improved to + cells.

Forty-eight hours later, she became asymptomatic, BCVA in her OS was 20/25, IOP was $13 \mathrm{~mm} \mathrm{Hg}$, slight hyperemia was observed, chemosis had resolved, cornea was transparent and the anterior chamber showed faint inflammation, with pharmacological mydriasis. Sodium chloride treatment was withdrawn. A week later, BCVA in her OS was 20/20, IOP was 11 $\mathrm{mm} \mathrm{Hg}$ and biomicroscopy showed no inflammation signs.

E. grandicornis sap content analysis was performed using dissolvent extraction spectrophotometry (Laboratorio de Bioquímica, Departamento de Ciencias Biológicas, Instituto Politécnico Nacional, Mexico). Euphorbia sap had a pH of 6.0, and its contents included flavonoids, alkaloids, phenols, and sesquiterpene lactones.

\section{Discussion}

The genus Euphorbia englobes more than 2,000 species distributed all around the world, mainly in template and subtropical regions. Some are characterized by thick, succulent branches and thorns; differed from cacti by their flowers and milky sap rich in irritant dipertene esters and carcinogens [1]. E. grandicornis belongs to the Euphorbiaceae family and it is commonly known as 'cows' horn'. The succulent Euphorbiae occur in India, Arabia, through Africa and Malagasy to the Cape [1]. One of the chief taxonomic features of Euphorbias is the quaint, complex floral arrangement called cyathium, which means 'cup', and this is 
Gómez-Valcárcel and Fuentes-Páez: Euphorbia grandicornis Sap Keratouveitis: A Case Report

the unit of the inflorescence [1]. A pinprick on the Euphorbia stem produces a trickle of white, milky latex, often poisonous.

Euphorbia sap ocular inflammation includes conjunctivitis, keratitis, and keratouveitis without posterior segment involvement. Initial symptoms include lacrimation, pain, and photophobia with worsening symptoms and visual acuity several hours after initial sap contact, as in this case [3]. Severe keratouveitis has been associated with exposure to the sap of several Euphorbia species, including lactea, royleana, lathyris, trigona, tirucalli, peplus, cyparissias, and helioscopia but not E. grandicornis [2-4]. Symptoms begin immediately after contact with the sap; patients refer burning pain, photophobia and lacrimation that worsen despite treatment; central corneal epithelial defect develops $24 \mathrm{~h}$ later and takes several days to heal [3, 4]. Ocular inflammation seems to be associated with the amount and time of sap exposure as well as the species; it is becoming apparent that some species are more toxic than others [3]. This patient did not develop a corneal epithelial defect, as happened after exposure to other Euphorbia sap species [2-4]. It has been reported that ingenol 3,20dibenzoate, a diterpenoid diester, a major component of sap from Euphorbia esula extract, has antileukemic activity. The corneal epithelial defects, requiring several days to heal in other reported cases, may be explained by the antineoplastic effects of the sap, which may hinder corneal epithelial replication [3]. Our patient did not have corneal epithelial defect, maybe because this compound was not present in E. grandicornis sap. This patient's clinical evolution resolved after 1 week, with complete recovery of visual acuity, as has been previously reported in other cases of Euphorbia sap keratouveitis [3].

Studies show that the corneal endothelium has a pH tolerance between 6.8 and 8.2. We reported a pH of 6 for Euphorbia sap, and its alkalinity would explain its increased corneal permeability through nonionic diffusion [5]. E. grandicornis sap toxicity can also be attributed to its flavonoids, alkaloids, phenols, and sesquiterpene lactones. Phenols, alkaloids and sesquiterpene lactones are liposoluble and thus, due to their hydroxyl groups, can easily cross epithelial cellular membranes and penetrate the entire cornea into the anterior chamber. Although E. grandicornis sap constituents have not been previously reported, flavonoids belonging to other species are antioxidants which can modify eicosanoids synthesis, block the $\mathrm{Na} / \mathrm{K} / \mathrm{ATPase}$ pump, show promise as a treatment for dry eye, and have anti-HBV activity in animal studies $[6,7]$.

E. grandicornis sap corneal exposure is a cause of nonvisually threatening keratouveitis when adequately treated with corticosteroids.

\section{Acknowledgments}

The authors thank Jerónimo Reyes-Santiago, MSc, Instituto de Biología de la UNAM, Mexico, who identified the genus and species of the plant.

\section{Statement of Ethics}

The authors have no ethical conflicts to disclose. 
Case Reports in

Ophthalmology

\section{Disclosure Statement}

None of the authors has any conflicts of interest to disclose. No author has financial or proprietary interest in any material or method mentioned.

\section{References}

Court D: Succulent flora of Southern Africa. Struik Publishers (Pty) Ltd., South Africa, 2011.

12 Merani R, Sa-Ngiampornpanit T, Kerdraon Y, Billson F, McClellan KA: Euphorbia lactea sap keratouveitis: case report and review of the literature. Cornea 2007;26:749-752.

-3 Eke T, Al-Husayni S, Raynor MK: The spectrum of ocular inflammation caused by euphorbia plant sap. Arch Ophthalmol 2000;118:13-16.

-4 Scott IU, Karp CL: Euphorbia sap keratopathy: four cases and a possible pathogenic mechanism. Br J Ophthalmol 1996;89:823-826.

-5 Fuchsjäger-Mayrl G, Zehetmayer M, Plass H, Turnheim K: Alkalinization increases penetration of lidocaine across the human cornea. J Cataract Refrac Surg 2002;28:692-696.

-6 Choi SM, Seo MJ, Lee YG, Lee MJ, Jeon HJ, Kang KK, Ahn BO, Yoo M: Effects of DA-6034, a flavonoid derivative, on mucin-like glycoprotein and ocular surface integrity in a rabbit model. Arzneimittelforschung 2009;59:498-503.

7 Tian Y, Sun LM, Liu XQ, Li B, Wang Q, Dong JX: Anti-HBV active flavone glucosides from Euphorbia humifusa Willd. Fitoterapia 2010;81:799-802.

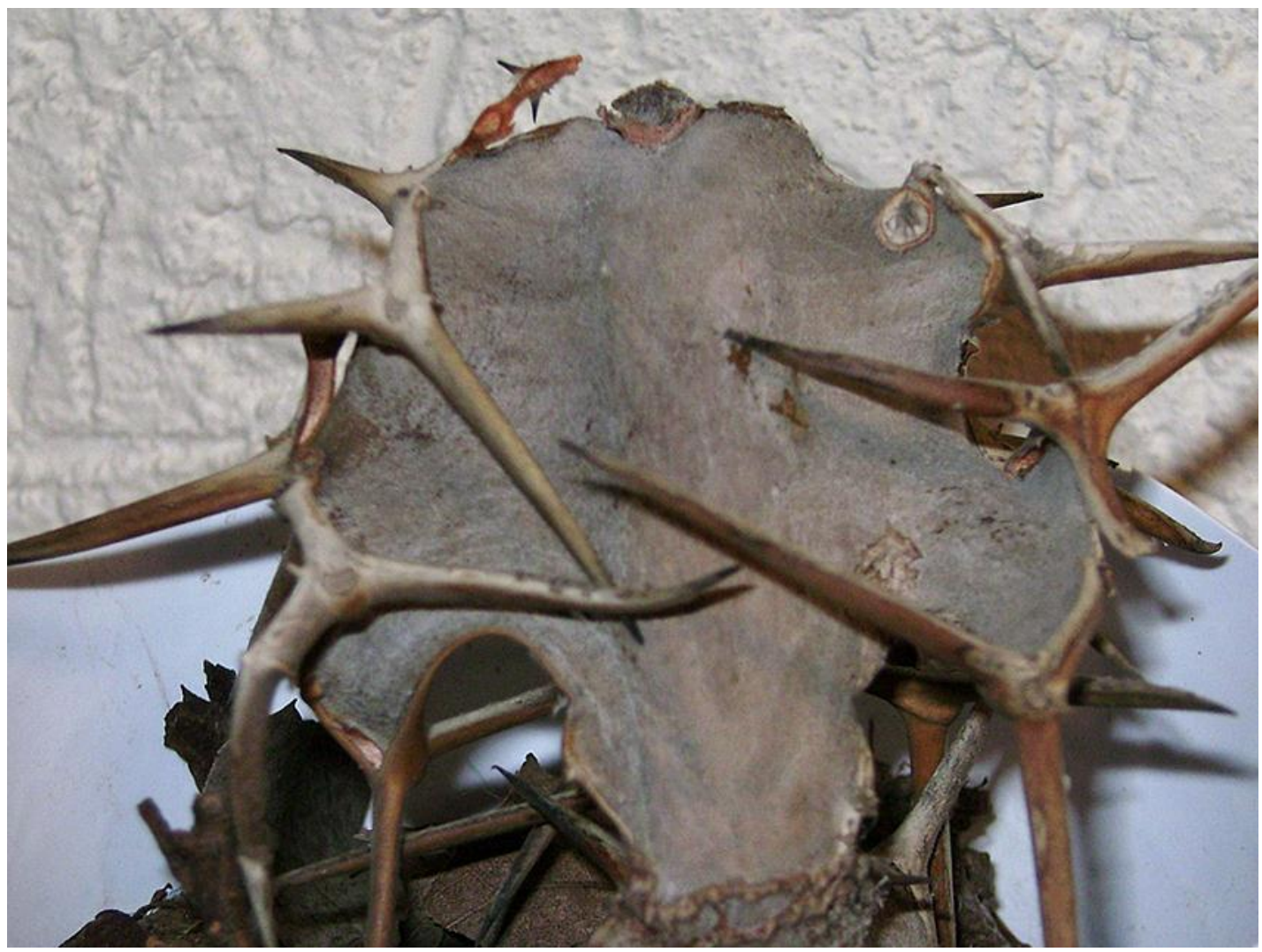

Fig. 1. E. grandicornis belonging to the patient, with strong spines resembling the shape of cows' horns. It is used for ornamental purposes. 
Gómez-Valcárcel and Fuentes-Páez: Euphorbia grandicornis Sap Keratouveitis: A Case Report
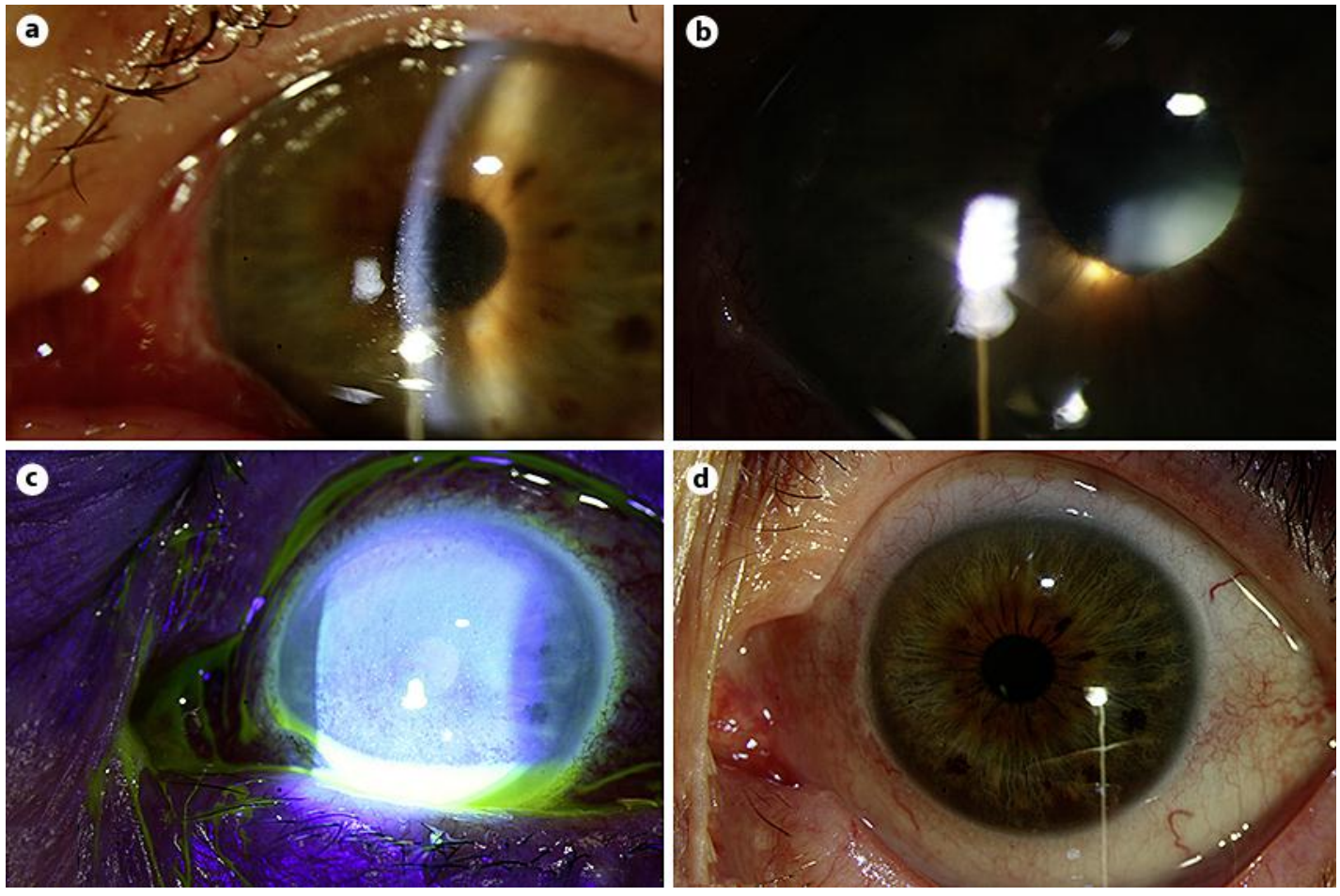

Fig. 2. Slit-lamp photograph of the OS. a Clinical aspect after $24 \mathrm{~h}$ of exposure to Euphorbia sap. b Anterior chamber inflammation. c Corneal fluorescein staining. d Clinical aspect 1 week later. 